\title{
A relação com o escrito nos kits de identidade de adultos em processos de reconhecimento e certificação de competências
}

\author{
Maria de Lourdes Dionísio* \\ Rui Vieira de Castro* \\ Ana Silva**
}

\begin{abstract}
Resumo
No âmbito de um projeto de pesquisa centrado nas biografias de relação com o escrito de adultos envolvidos, em Portugal, em processos de Reconhecimento, Validação e Certificação de Competências - RVCC -, neste texto apresentamse os dados relativos à inquirição a 113 adultos do distrito de Braga, Portugal, os quais, estavam a iniciar este processo de reconhecimento. Assume-se que as práticas de linguagem são indissociáveis dos contextos socioculturais em que as pessoas se movimentam, e que as práticas de leitura e escrita atravessam todos os diferentes domínios de vida, de modos mais ou menos vernáculos por oposição aos dominantes definidos por instituições como a escola. Entre as principais conclusões, destaca- -se nestes sujeitos, tidos como "iletrados", a presença e variedade de atividades de interação com textos, por meio de textos e sobre textos. As características de tais atividades andam intimamente ligadas aos domínios de vida em que estes sujeitos participaram e participam. Neste sentido, a frequência e finalidade do RVCC contribuem para acrescentar aos kits de identidade destes cinco adultos, os traços, e valores que as comunidades letradas atribuem, sobretudo, à leitura.
\end{abstract}

Palavras-chave: Adultos. Identidades letradas. Competências. Interação.

\footnotetext{
*Professora catedrática, Centro de Investigação em Educação, Universidade do Minho, Braga, Portugal. Este texto foi produzido no âmbito do Projeto "A vida em mudança: a literacia na educação de adultos" (PTDC/CPECED/ 105258/2008), em desenvolvimento no Centro de Investigação em Educação (CIEd) da Universidade do Minho e no Centro de Investigação Sobre o Espaço e Organizações (CIEO) da Universidade do Algarve, com financiamento de fundos nacionais, através da FCT/MCTES (PIDDAC) e cofinanciamento do Fundo Europeu de Desenvolvimento Regional (FEDER) através do COMPETE - Programa Operacional Fatores de Competitividade (POFC).

** Doutoranda, Centro de Investigação em Educação, Universidade do Minho, Braga, Portugal.
} 


\section{A literacia enquanto prática social}

Apesar de muitas evidências em contrário (GRAFF, 1979; CARRINGTON; LUKE, 1997), nas sociedades contemporâneas está fortemente enraizada a convicção de que a prosperidade dos países depende dos níveis de literacia das populações, ou, nas palavras de Mary Hamilton e Kathy Pitt (2011), que um dos indicadores de progresso é a literacia. Na medida em que esta crença posiciona os adultos, sem ou com pouca escolarização, quase "como marginais" e "socialmente excluídos" (HAMILTON; PITT, 2011, p. 350), a sua "falta de literacia" constitui uma preocupação de políticas sociais e económicas que se têm traduzido em medidas e programas que tanto visam a administração direta de "literacia", isto é, que instituem a leitura e a escrita como objeto de aprendizagem, como, junto com a numeracia, visam o desenvolvimento do que ficou conhecido como "skills básicos" (HAMILTON; HILLIER, 2006, p. 22) administrados a par de disciplinas escolares. É neste quadro de discursos e políticas sobre a necessidade de certificação da população para, por um lado, o desenvolvimento económico e, por outro, para que os adultos possam enfrentar o "ambiente global, competitivo e em rápida mudança da economia do conhecimento" (GEE; HULL; LANKSHEAR, 1996, p. 4) que assistimos, em Portugal, à criação dos Centros Novas Oportunidades e, neles, ao processo de Reconhecimento, Validação e Certificação de Competências -RVCC-.

Destinado a equiparar formalmente as competências adquiridas pelos indivíduos ao longo da vida (em sentido lato, englobando a esfera pessoal, profissional, social) às qualificações académicas concedidas pelo sistema formal de ensino, nos níveis Básico e Secundário, o RVCC foi o maior programa de qualificação escolar e/ou profissional de adultos em Portugal, que teve lugar entre 2005 e 2011, esperando certificar cerca de um milhão de sujeitos.

Este programa político concretiza ideias dominantes em Portugal nos debates e nas políticas de educação de adultos: a 'educação e formação ao longo da vida'; o 'reconhecimento e validação de competências"” (RODRIGUES; NÓVOA, 2005, p. 11), colocando em destaque a importância das aprendizagens realizadas nas experiências de vida, reconhecendo esta como um contexto válido de 
aprendizagem e de desenvolvimento de competências. Para o reconhecimento e certificação, os adultos passam por um processo de reflexão, isto é, a partir de um olhar retrospectivo sobre as suas vivências e experiências, identificam possíveis conhecimentos e competências que daí resultaram. E é aqui, entre o que os adultos trazem das suas vidas e o que devem saber, que as práticas de literacia assumem um duplo estatuto: o de meio e fim das aprendizagens. E se tal hipótese sobre o papel da literacia no processo é confirmada no discurso político e pedagógico oficial, também nos processos e modalidades que concretizam o programa, se institui a literacia como eixo essencial de ação (CASTRO; LARANJEIRA, 2009; GOMES, 2006).

A fundamentar a implementação do RVCC e de outras iniciativas formativas orientadas para adultos está, contudo, uma visão da leitura e da escrita enquanto técnicas e capacidades que se adquirem independentemente dos contextos onde são produzidas e usadas. Neste sentido, parece pressupor-se que o ato interpretativo de qualquer tipo de texto está exclusivamente associado a capacidades cognitivas - que, no essencial, se prendem com o conhecimento da língua, o qual, uma vez adquirido, pode ser aplicado em qualquer circunstância de vida. A esta concessão instrumental dos usos da escrita, Street $(1984 ; 1995 ; 2005)$ chamou "modelo autónomo", por oposição à perspetiva sócio-histórica e identitária que veio a designar de "modelo ideológico". ${ }^{1} \mathrm{O}$ modelo ideológico entende a literacia como um conjunto de práticas sociais, histórica e culturalmente situadas, e observáveis em eventos mediados por textos, refutando, dessa forma, a sua conceção enquanto capacidade de decifração de textos escritos, ou seja, como algo técnico, resultado de skills independentes (LUKE; FREEBODY, 1999; GEE, 2005).

Nesta linha de pensamento, adotada pelos "Novos estudos de literacia", as práticas de literacia - unidades básicas de uma teoria social da literacia (BARTON; HAMILTON; IVANIČ, 2000) - são modos culturais de utilização da linguagem escrita a que as pessoas recorrem diariamente. Estas práticas moldam os eventos de literacia, isto é, os episódios observáveis onde a literacia assume um papel específico e em que os textos fazem parte das interações e dos processos de interpretação dos sujeitos. ${ }^{2}$ Em tais eventos, os modos como se usam também em Dionísio (2006); Fischer (2007); Keating (2002) e Torrão (2007), estão desenvolvidos e 
os textos variam, podendo estes apresentar características, não exclusivamente linguísticas, mais próximas ou mais afastadas das instituições sociais que definem o que é legítimo dizer e fazer com a linguagem. Nesse quadro, ser letrado num determinado domínio de prática é possuir e poder exibir um "bilhete de identidade" que inclui traços pessoais não apenas relativos às habilidades e processos de manipulação da palavra escrita, mas também, de acordo com Gee (2005), Dionísio (2006) e Dionísio e Castro (2009), aos comportamentos, valores, crenças e saberes, por vezes tácitos, sobre o que pode ser dito e feito, como e com que 'acessórios', naquele domínio particular. Nesta teoria social, pressupõe-se, assim, que as práticas de uso de textos não apresentam sempre as mesmas características em todos os contextos, variando conforme as distintas esferas de vida: a familiar, a laboral, etc. Como nos mostram Barton, Ivanič, Appleby, Hodge e Tusting (2007), cada uma destas esferas mobiliza a linguagem social e identidade que lhe são específicas, isto é, os modos 'preferidos' de, naquela esfera, fazer sentidos com os textos, formas particulares de os usar e, mesmo, de sobre eles falar.

A possibilidade de adquirir, aprender e exibir os traços identitários de cada esfera - o pai de família, o trabalhador, o membro do clube recreativo, ... - resulta, pois, de vários processos de socialização, segundo as normas e ideologias das instituições ou grupos que configuram os contextos onde os sujeitos atuam. Daqui se depreende que é do envolvimento nos eventos de literacia que ocorrem nas diferentes esferas - moldados não só por "práticas dominantes", que apresentam características muito próximas das de instituições formais como a escola, mas também por "práticas vernáculas", geralmente pouco valorizadas porque enraizadas na experiência quotidiana - que resulta a transformação das identidades letradas dos sujeitos: suas linguagens, modos de aceder, usar e valorizar os textos.

exemplificados os conceitos de práticas e eventos de literacia. 


\section{A literacia na vida dos adultos: um estudo empírico}

É com base no anterior enquadramento, e com o intuito de compreender até que ponto são (e como são) desafiadas e transformadas as práticas vernáculas de usos de textos e, em consequência, que transformações se operam nas identidades letradas de adultos que chegam ao processo de RVCC com o objetivo de obter o nível Básico de escolaridade ( $9^{\circ}$ ano) que se levou a cabo o projeto de investigação "A vida em mudança. A literacia na educação de adultos". Partilhando dos princípios que fundamentam a perspetiva social de literacia, pretendeu-se com este estudo compreender as literacias dos sujeitos num quadro de pressupostos em que avultam: a sua multiplicidade, dada a associação intrínseca a diversos domínios de vida; a sua natureza motivada, porque meio de outras práticas culturais mais vastas; a sua variabilidade e transformação, por ação de processos de aprendizagem tanto formais como informais.

Para responder a estes objetivos, o estudo, no seu desenho, previu genericamente três momentos, definidos pela relação dos indivíduos com o processo de RVCC: o antes, o durante e o após a formação. Neste texto apresentam-se, apenas, os dados recolhidos por questionário na primeira fase.

$\mathrm{O}$ inquérito visou reconstituir as trajetórias de literacia dos adultos, isto é, as práticas, atitudes, valores e conceções de literacia que constituem e definem as identidades dos adultos quando ingressam no processo de RVCC. Neste sentido, identificou-se o lugar que ocupam, nas vidas destes adultos, a leitura e a escrita, ou seja o que escrevem e leem no seu quotidiano e com que finalidades, procurando-se contribuir para a desconstrução do entendimento da leitura e da escrita enquanto técnicas e capacidades - ainda fortemente enraizado no discurso público - apresentando-as, antes, como atividades sociais variáveis e complexas que ocorrem em relações sociais também complexas.

Expostas as assunções teóricas e as orientações gerais de investigação do estudo que aqui se apresenta, enunciam-se sucintamente, a seguir, os procedimentos metodológicos adotados e procede-se à caracterização dos adultos que constituíram a amostra, terminando-se com a discussão do papel da literacia nas suas vidas, a partir da descrição de "o quê, para quê e em que contextos" leem e escrevem. 


\section{Procedimentos metodológicos}

Os dados que aqui são mobilizados para a análise do modo como adultos, de novo implicados num contexto formal de educação, usam a literacia no seu dia a dia, resultam da inquirição por questionário a 113 adultos do distrito de Braga, Portugal, os quais, no momento em que davam entrada nos CNOs e eram encaminhados para o processo de Reconhecimento, Validação e Certificação de Competências, se disponibilizaram a colaborar com o estudo.

Por meio de 28 questões, organizadas em função de dois grandes marcos temporais (o tempo de frequência da escola e o período de aí em diante até aos dias de hoje), solicitava-se aos sujeitos informação sobre alguns aspetos das suas práticas de uso de textos escritos, com o objetivo de aceder às suas biografias de literacia, aos modos como usam a leitura e a escrita nos diferentes domínios sociais em que se movimentam e suas principais finalidades.

Dadas as circunstâncias político-sociais do momento em Portugal e a pouca afluência de indivíduos aos Centros de Novas Oportunidades, a constituição da amostra foi aleatória, regendo-se apenas pelo critério de serem sujeitos que iniciavam naquela altura o processo de diagnóstico para a entrada num RVCC. Consequentemente, os adultos deste estudo não se distinguem, por exemplo, por pertencerem a grupos etários particulares: a maior parte situa-se entre os 54 a 58 anos, tendo o mais jovem 18, e o mais velho, 66. Pela mesma razão, apenas por coincidência, a distribuição por género é equilibrada: 55 homens e 57 mulheres. A grande maioria (cerca de 80\%) encontra-se atualmente em situação de desemprego, sendo que $13,3 \%$, ainda que no ativo, ocupa postos de trabalho pouco qualificados e mal remunerados (dos 13 sujeitos empregados que assinalaram a sua ocupação profissional, 10 são operários em fábricas têxteis e três desempenham tarefas na área do comércio e serviços). A precária situação laboral de uma expressiva fração destes indivíduos justifica-se pelo contexto social onde vivem e actuam ${ }^{3}$ e pelas

3 Mais de metade dos inquiridos reside em Guimarães, numa região, no norte de Portugal - o Vale do Ave -, cuja economia é fundamentalmente suportada pela indústria têxtil. Com a crise económica instalada, muitas das fábricas do setor foram obrigadas a encerrar, deixando no desemprego grande parte da população. Agudiza a situação, o facto de muitos destes desempregados, incluindo uma expressiva fração dos sujeitos inquiridos, possuírem apenas o 1 ㅇ Ciclo (os primeiros quatro anos) do Ensino Básico. 
baixas qualificações académicas, a exigir a sua presença no processo de educação e formação de adultos.

Em termos de habilitações e frequência escolares, 50,4\% dos adultos da amostra frequentaram o $4^{\circ}$ ano de escolaridade, $4,5 \%$ não chegaram sequer ao $4^{\circ}$ ano, $23 \%$ frequentaram o $5^{\circ}$ e $6^{\circ}$ anos e $20,4 \%$, os anos subsequentes ( $7^{\circ}$ ao $9^{\circ}$ ). Ainda que, dos 57 sujeitos que frequentaram o $4^{\circ}$ ano, apenas 24 tenham andado entre 5 a 7 anos na escola, é possível constatar que o percurso escolar da maioria dos inquiridos foi marcado pelo 'fracasso' (se se tomarem como referência os 13 indivíduos que chegaram ao $3^{\text {o }}$ Ciclo do Ensino Básico, verificamos que apenas dois frequentaram a escola pelo período esperado de 9 anos, precisando os restantes de 10 a 12 anos).

As razões que levaram estes adultos a abandonar precocemente a escola estão igualmente associadas ao contexto social onde cresceram: dificuldades económicas $(40,7 \%)$ e, em sua estreita dependência, a atitude impositiva dos pais, que os terá "compelido" a desistir dos estudos (8\%). Além disso, ainda que sempre associado às condições socioeconómicas, a tradição cultural de alguns destes indíviduos, sobretudo dos mais velhos, considerava suficientemente escolarizado aquele que frequentava apenas o $1^{\circ}$ ciclo, saindo-se do sistema escolar assim que este era completado. Esta "tradição" é, aliás, uma das razões que levou 10,6\% dos adultos a deixarem de estudar para darem início à sua carreira laboral.

\section{Literacias, finalidades e contextos}

A perspetiva social de literacia, que, como vimos, rejeita liminarmente qualquer visão da leitura e da escrita enquanto habilidades exclusivamente psicocognitivas, concebe, como se aprende com Barton (1994) e Barton e Hamilton (1998), os usos de textos como atividades humanas de natureza social. Neste sentido, práticas de leitura e escrita incluem tudo aquilo que as pessoas fazem com os textos, nas suas mais diversas formas, no seu dia a dia e nos diferentes eventos sociais em que se envolvem. Tendo em consideração a multiplicidade de finalidades existentes para o uso de textos e, portanto, também a multiplicidade de modos como se usam os textos, pressupõe-se que a literacia não é a mesma em todas as esferas de vida, 
podendo inclusivamente sofrer variações ao longo do tempo.

Tal variação e multiplicidade ficam demonstradas se atentarmos na vida destes 113 homens e mulheres, naquilo que trazem para o processo de RVCC. Desde logo percebemos que o seu quotidiano é marcado pelo escrito, surgindo a leitura como uma prática social mais generalizada, comparativamente à escrita: apenas a redação de recados, cartas, notas, mensagens no telemóvel e na Internet, a par de apontamentos pessoais, são práticas frequentes na vida dos inquiridos, maioritariamente utilizadas como forma de estabelecer comunicações a distância, de tratar de situações do dia a dia e de distração. Ainda assim, é de referir que estas práticas de escrita são em maior número do que as da sua vida passada, reduzidas que estavam, sobretudo, à produção de trabalhos escolares.

Relativamente à leitura - seja para informação, organização pessoal, lazer ou aprendizagem de coisas novas -, os adultos inquiridos afirmam ler frequentemente jornais, revistas, rótulos de produtos, contas, faturas, recibos, folhetos de publicidade, legendas de televisão, recados, cartas, mensagens de telemóvel, horários, mapas, instruções, avisos, comunicados, documentos oficiais e relatórios. Fora da frequência regular, encontram-se os livros técnicos e de histórias - que, ainda assim, mais de metade dos sujeitos $(58,3 \%)$ dizem ler 'às vezes' ou 'muitas vezes'.

Na medida em que, com a entrada na fase adulta, vem também a assunção de novos papéis sociais que implicam, inevitavelmente, o envolvimento em novas práticas de literacia, não é de estranhar que a leitura de contas, faturas e recibos seja hoje uma atividade que $76,1 \%$ dos sujeitos revelem fazer assiduamente e que a leitura de manuais escolares permaneça agora, e ao contrário do que aconteceu na infância e juventude, como uma prática pouco habitual nas suas vidas. Deste modo, se, antes, liam quase exclusivamente para fins escolares (apenas por vezes recreativos, com a leitura de jornais e de revistas), atualmente a leitura está muito mais presente nas suas vidas sobretudo para darem resposta às necessidades reais do seu quotidiano.

Dada a natureza das práticas, podemos concluir que prevalecem na vida destes sujeitos as suas práticas vernáculas - aquelas que, geradas no quotidiano, não são reguladas pelas regras formais e procedimentos das instituições sociais dominantes. E cremos ser precisamente esta sua natureza privada, doméstica e 
familiar que leva a que muitas vezes as não identifiquem e reconheçam como práticas de leitura e de escrita tão válidas quanto outras, específicas de domínios como o escolar: as práticas dominantes. Será por isto que, embora estes adultos leiam e escrevam com regularidade nas diferentes esferas das suas vidas, não consideram as suas práticas legítimas (e até 'dignas') conforme atestam relatos como: "Peço desculpa se alguma coisa estiver mal, pois desde que saí da escola que a minha escrita nunca foi instruída".

As respostas à questão sobre o que leram e escreveram em dois dias da semana previamente selecionados (terça-feira e domingo), aparecem intimamente relacionadas com a visão que têm de si próprios enquanto sujeitos (não) letrados. $\mathrm{Na}$ verdade, ainda que alguns admitam ler jornais/revistas nas manhãs de terçafeira, a maioria não declara qualquer tipo de prática de literacia nos restantes períodos do dia, o mesmo acontecendo nos domingos.

Por isto, os espaços reservados a esta pergunta, no questionário, surgem quase sempre em branco ou com comentários como: "Não li/não escrevi nada". Poderá ser já a adaptação ao contexto em que se encontram - o Centro de Novas Oportunidades, decorado com cartazes sobre a importância da leitura e atravessado pelos discursos dos formadores sobre a importância da instrução escolar, que leva à avaliação negativa da sua identidade e à "apropriação" de um discurso marcado pela conceção dominante de que a leitura que "conta" socialmente é a leitura de livros e não a que eles habitualmente realizam e reportam.

No mesmo sentido, poderá decorrer desta apropriação da visão dominante a necessidade destes sujeitos em mencionarem o tipo de livros que preferem: "O que mais faço normalmente é ler livros de todo o género de leitura, mais policiais", a par de razões que justificam a relativa ausência desta prática nas suas rotinas diárias: "Muitas vezes não leio mais livros por falta de tempo".

No entanto, este sentimento de deficit, por parte dos adultos, relativamente a práticas que têm como legítimas, atribuído ao facto de não possuírem níveis de escolarização mais elevados, e que, no questionário e em conversas, vão revelando, tende a ser ocultado noutras respostas. Assim, ao serem interrogados sobre se sentem dificuldades quando leem e escrevem, 54\% afirmam que "não" e $88,5 \%$ que só "às vezes". Do mesmo modo, quando lhes é solicitado que avaliem as suas competências de leitura e de escrita, apenas $17,7 \%$ as classificam como 
"insuficientes", enquanto a maioria as considera "suficientes" ou "plenamente suficientes".

Constata-se, todavia, que, em questões sobre dificuldades na leitura de textos específicos (os mesmos que se lhes pedia que assinalassem se os liam e escreviam), são em grande número os inquiridos que afirrmam ter "muitas" dificuldades quando leem livros técnicos, comunicados, documentos oficiais, manuais de instruções, informação na Internet, mensagens de telemóvel e e-mails. Já os textos onde mencionam ter "poucas" ou "nenhumas" dificuldades correspondem, previsivelmente, aos que estão presentes na sua vida diária, como os jornais, as contas, as faturas e recibos, as legendas de televisão, os folhetos de publicidade, entre outros.

Colocados, desta forma, numa situação de conflito entre o que consideram que são enquanto sujeitos de literacia e aquilo que representam como devendo ser, naturalmente com vista à "autorização" plena das suas biografias (consignada na atribuição do diploma escolar), pressentem-se, no discurso destes 113 adultos, alguns ajustamentos aos contextos em que julgam que têm de ser bem-sucedidos. Isto é desde logo visível quando 53 deles mencionam ter só “às vezes" dificuldades de leitura e 95 afirmam que, se tivessem mais habilitações, compreenderiam melhor os textos que têm de ler. Manifesta-se ainda quando, no quadro de leituras mencionadas (maioritariamente instrumentais), 81 (71,7\%) adultos declaram que ler é algo que sempre gostaram de fazer, verificando-se, no entanto, que, no domínio das atividades com que ocupam os seus tempos livres, a leitura é assinalada como "pouco" ou "nada" frequente por $44,3 \%$ dos sujeitos.

Este posicionamento de adequação às características que consideram identitárias dos "insiders" (GEE, 2005) destas comunidades educativas: quem frequenta a escola gosta (e tem de gostar) de ler, quem é "certificado" valoriza a leitura, é ainda percetível nas afirmações relativas i) ao valor da leitura e da escrita no quotidiano de cada um e ii) à relevância dessas práticas para uma plena participação comunitária. Qualquer dos casos acolhe a quase unanimidade de opiniões "concordantes" e "totalmente concordantes".

Se no caso da referência frequente à leitura de jornais e revistas podemos ver o investimento cultural possível neste grupo ou, na esteira de Setton (2005), as "estratégias de adquirir os bens da cultura e do conhecimento e de ter acesso a 
estes" (p. 80), no caso dos valores e atitudes poderemos estar face a estratégias de simulação de uma imagem de leitor a que Aliagas, Castellà e Cassany (2009, p. 109) chamam "fórmulas de mitigação que visam mudar as perceções dos outros sobre as identidades letradas" de cada um.

\section{Conclusão}

Cada indivíduo é uma combinação única de identidades, resultante de experiências sociais diversas, ao longo da vida. É a partir do envolvimento em distintas práticas sociais, nos vários contextos de vida, que os sujeitos adquirem habilidades e processos de uso de textos escritos, mas também atitudes, saberes, valores e crenças sobre o que pode ser dito e feito, como e com que recursos, num determinado evento de literacia.

Embora reconhecendo-se que a participação dos sujeitos em situações de aprendizagem diversificadas desencadeia novos modos de aceder, usar e valorizar os textos, tende-se a considerar somente como válidas e legítimas as práticas de literacia que resultam, especificamente, do domínio escolar. Neste sentido, são frequentemente desvalorizadas e esquecidas as experiências textuais dos indivíduos com origem nas práticas do dia a dia, que, muitas vezes, são determinantes na resposta às exigências sociais.

Os dados que aqui se apresentaram corroboram, uma vez mais, a perspetiva dinâmica e multifacetada que caracteriza o relacionamento dos indivíduos com as literacias de contextos formais e informais, reconhecendo as práticas vernáculas - que moldam o nosso quotidiano enquanto indivíduos e cidadãos, no âmbito da aprendizagem ao longo da vida - como parte integrante, e fundamental, das vidas letradas dos adultos.

Assim, muito mais do que adquirir e mobilizar skills de (des)codificação do escrito, tendencialmente associados ao domínio escolar e a capacidades que se creem representativas do ser-se "letrado", estão em jogo os modos específicos de reconhecimento e edificação das práticas literácitas por parte dos indivíduos. E é, pois, procurando contribuir para o desmantelamento das representações ainda dominantes e criar condições para a compreensão dos pluridimensionais e 
complexos processos de construção de sujeitos "letrados", que, neste olhar breve, devolvemos a cada um (de nós todos) a primordial tarefa de reconhecer e validar, certificando, as competências de ler e escrever o (seu) próprio mundo.

\title{
The relation with writing in the kits of adults' identity in the recognition and competences certification processes
}

\begin{abstract}
In the scope of a research project which focuses on the biographies of adults from Portugal engaged in recognition, validation and competences certifying (RVCC) processes, emphasizing their relation with writing, this paper presents the data related to the inquiry of 113 adults from Braga district, Portugal, who were at the beginning of this recognition process. It is assumed that the language practices are inseparable from the sociocultural contexts in which people move themselves on, and that the reading and writing practices go through all the different dominions of life, in more or less vernacular ways which go against the dominant ones that are defined by institutions such as schools. Among the main conclusions, it is standed out that these participants, considered "illiterates", show the presence and variety of interaction activities with texts, through texts and about texts. These activities characteristcs are closely connected to the areas of life in which these subjects took and take part in. In this perspective, the frequency and gols of RVCC contribute to add to the identity kits of these five adults, the features and values that the community attributes, mainly, to the reading. Keywords: Adults. Literate identities. Competences. Interaction.
\end{abstract}




\title{
Le rapport avec l'écrit dans les kits d'identité d'individus adultes en processus de reconnaissance et certification de compétences
}

\begin{abstract}
Résumé
Dans le contexte d'un projet de recherche basé sur les biographies de rapport avec l'écrit d'individus adultes concernés, au Portugal, en processus de Reconnaissance, Validation et Certification de Competétences (RVCC), on présente dans ce texte les donnés relatives à l'enquête avec la partcipation de 113 adultes du district de Braga, Portugal en début de processus de reconnaissance. On assume que les pratiques de langage ne sont pas indissociables des contextes sócio-culturels où les personnes se déplacent, et que les pratiques de lecture et écriture "traversent" tous les différents domaines de la vie, de manière plus ou moins vernaculaire par opposition aux dominantes définies par des institutions tels que l'école. Parmis les principales conclusions, on remarque chez ces individus perçus comme des "illetrés" la présence d'une variété d'activités d'intéraction avec les textes, par l'intermédiaire de textes et sur des textes. Les caractéristiques de ces activités se rapportent intimement aux domaines de vie partagés par ces sujets. Dans ce sens, la fréquence et finalité du RVCC contribuent à ajouter aux kits d'identité de ces adultes, les traits et les valeurs que les communautés lettrées attribuent, surtout, à la lecture.
\end{abstract}

Mots-clés : Adultes. Identités letrées. Compétences. Interaction.

Referências

ALliagAS, Cristina; CASTEllÀ, Josep M.; CASSANY, Daniel. Aunque lea poco, yo sé que soy listo. Estudio de caso sobre un adolescente que no lee literatura. OCNOS, Cuenca, 5, p. 97-112, 2009.

BARTON, David. Literacy: an introduction to the ecology of written language. London: Blackwell Publishers, 1994. 247 p. 
BARTON, David; HAMILTON, Mary. Local literacies: reading and writing in one community. London/New York: Routledge, 1998. 299 p.

BARTON, David; HAMILTON, Mary; IVANIČ, Roz. Situated literacies: reading and writing in context. London/New York: Routledge, 2000. 222 p.

BARTON, David; IVANIČ, Roz; APPLEBY, Yvon; HODGE, Rachel; TUSTING, Karin. Literacy, lives and learning. London/New York: Routledge, 2007. 180 p. CARRINGTON, Victoria; LUKE, Allan. Literacy and Bourdieu's sociological theory: a reframing. Language and education. London, v. 11, n. 2, p. 96-112, Jul., 1997.

CASTRO, Rui; LARANJEIRA, Rómina. Educação e formação de adultos em Portugal. Concepções de literacia no discurso pedagógico oficial. Fórum. Braga, 42-43, p. 95-110, 2009.

DIONÍSIO, Maria de Lourdes. Educação e literacias. Relatório da disciplina. Grupo Disciplinar de Metodologias da Educação do Departamento de Metodologias da Educação - Instituto de Educação da Universidade do Minho. Braga (manuscrito não publicado), 2006. 119 p.

DIONÍSIO, Maria de Lourdes; CASTRO, Rui Vieira de. (Re)defining literacy: new roles of the workplace. In: BRON JR., Michal; GUIMARÃES, Paula; CASTRO, Rui Vieira de. The state, civil society and the citizen. Exploring relationships in the field of adult education in Europe. Frankfurt am Main: Peter Lang, 2009. p. 185-195.

FISCHER, Adriana. A construção de letramentos na esfera académica. 340 p. Tese (Doutorado em Linguística). Universidade Federal de Santa Catarina. Florianópolis, 2007.

GEE, James Paul. La ideología en los discursos. Lingüistica social y alfabetizaciones. Madrid: Ediciones Morata, 2005. 231 p.

GEE, James; HULL, Glynda; LANKSHEAR, Colin. The new work order: behind the language of the new capitalism. boulder, CO: Westview Press, 1996. 202 p.

GOMES, Maria do Carmo (Coord.). Referencial de competências-chave para a educação e formação de adultos - Nível secundário. Lisboa: Direcção Geral de Formação Vocacional, 2006. 92 p.

KEATING, Maria Clara. O poder de dar nome às coisas: sobre reconhecimentos e aprendizagens em práticas e discursos. Revista Portuguesa de Educação, Braga, v. 15, n. 2, p. 131-167, 2002. 
GRAFF, Harvey. The literacy myth: literacy and social structure in the 19th century city. London: Academic Press, 1979. 353 p.

HAMILTON, Mary; PITT, K. Challenging representations: constructing the adult literacy learner over 30 years of policy and practice in the United Kingdom. Reading research quarterly, 46, 4, p. 350-373, 2011.

HAMILTON, Mary; HILLIER, Yvonne. Changing faces of adult literacy. language and numeracy: a critical history of policy and practice. London: Trentham Books, 2006. 208 p.

KLEIMAN, Angela Bustos (Org.). Os significados do letramento. Uma nova perspectiva sobre a prática social da escrita. Campinas, SP: Mercado de Letras, 1999. $294 \mathrm{p}$.

KLEIMAN, Angela Bustos 1. Trajetórias de acesso ao mundo da escrita: relevância das práticas não escolares de letramento para o letramento escolar. Perspectiva. Florianópolis, v. 28, n. 2, p. 375-400, 2010.

LUKE, Allan; FREEBODY, Peter. Further notes on the four resources model. Disponível em: <http://www.readingonline.org/research/lukefreebody.html>. Acesso em: 3 dez. 2010.

OCDE. Analfabetismo funcional e rentabilidade económica. Porto: Edições Asa, 1992. 142 p.

RODRIGUES, Cristina; NÓVOA, António. Prefácio. In: CANÁRIO, Rui; CABRITO, Belmiro (Org.). Educação e formação de adultos: mutações e convergências. Lisboa: Educa, 2005. p. 7-14.

SETTON, Maria da Graça Jacintho. Um novo capital cultural: pré-disposições e disposições à cultura informal nos segmentos com baixa escolaridade. Educação \& sociedade. Campinas, v. 26, n. 90, p. 77-105, jan./abr. 2005.

SOARES, Magda. Letramento: um tema em três gêneros. Belo Horizonte: Autêntica, 1998. 128 p.

STREET, Brian. Literacy in theory and practice. Cambridge, UK: Cambridge University Press, 1984. 243 p.

STREET, Brian. Social literacies: critical approaches to literacy in development, ethnography and education. London: Longman, 1995. 184 p.

STREET, Brian. Recent applications of New Literacy Studies in educational contexts. Research in the teaching of English. Michigan, v. 39, n. 4, p. 417-423, 2005 . 
TORRÃO, Maria João. Entre a escola e a vida. Percursos de literacia. 149 p. Dissertação (Mestrado em Educação: Supervisão Pedagógica em Ensino do Português). Instituto de Educação da Universidade do Minho. Braga, 2007. 


\section{Dossiê}

Letramentos e posicionamentos identitários: construção discursiva. 